\title{
Significant Reduction of Elevated Triglycerides and Liver Fibrosis in Diabetic Dyslipidemia with Saroglitazar: A Case Report
}

\author{
Sayak Roy ${ }^{1}$, Abhijnan Ghosh ${ }^{2}$ \\ 1. Internal Medicine, Calcutta Medical Research Institute Hospital, Kolkata, IND 2. Pharmacology, The Institute of \\ Post-Graduate Medical Education and Research, Kolkata, IND
}

Corresponding author: Sayak Roy, sayak.roy.123@gmail.com

\begin{abstract}
Metabolic disorders are characterized by pathologies like visceral adiposity, hypertension, type 2 diabetes mellitus (T2DM), dyslipidemia, impaired glucose tolerance, fatty liver, and so on, with insulin resistance being the main contributing factor. Insulin resistance and diabetes mellitus are commonly associated with elevated triglyceride levels. Among the available medications for treating metabolic disorders, only Saroglitazar has a dual peroxisome proliferator-activated receptor $a+\gamma$ action that can reduce high triglycerides and improve insulin sensitivity. This medication may also reduce liver fibrosis content. The present case report illustrates the efficacy of Saroglitazar in reducing hypertriglyceridemia and liver stiffness as assessed by shear wave elastography.
\end{abstract}

Categories: Endocrinology/Diabetes/Metabolism, Family/General Practice, Epidemiology/Public Health Keywords: hypertriglyceridemia, shear wave elastography, type 2 diabetes mellitus, saroglitazar

\section{Introduction}

In the last three decades, there has been an exponential growth in the incidence of type- 2 diabetes mellitus (T2DM) in India. The current prevalence of T2DM in India is $8 \%-10 \%$ of the total population with an additional $15 \%$ population having pre-diabetes [1]. Studies have reported that nine out of 10 patients with diabetes are dyslipidemic and that insulin resistance precedes the development of T2DM by decades [2]. Even the pattern of dyslipidemia is different in India as compared to the Caucasian population of the Western world. Low high-density lipoprotein (HDL) is the commonest type of dyslipidemia in India ( $72 \%)$, followed by high triglycerides (TG) ( $\sim 30 \%$ ). In comparison, high low-density lipoprotein (LDL) is the least common type of dyslipidemia ( $\sim 11 \%)$ [3]. Achieving glycemic and lipid goals remains a challenge in the clinical scenario. Saroglitazar is a dual peroxisome proliferator-activated receptor (PPAR) $a / \gamma$ agonist and is currently available in India for the treatment of diabetic dyslipidemia (DD). It is a potent and predominantly PPAR- $a$ agonist with moderate PPAR- $\gamma$ agonistic activity. PPARs are nuclear lipid-activated transcription factors that regulate the expression of various genes involved in the control of lipid and lipoprotein metabolism, glucose homeostasis, and inflammatory processes. PPAR- $\alpha$ activation by Saroglitazar increases the hepatic oxidation of fatty acids (FA) and reduces the synthesis and secretion of TG. This, in turn, increases the diversion of FA from peripheral tissues (e.g., skeletal muscle and fat tissue) to the liver. Saroglitazar also activates PPAR- $\gamma$ and regulates the transcription of insulin-responsive genes involved in the control of glucose production, transport, and utilization. By increasing the expression of these genes, Saroglitazar decreases the post-prandial rise of plasma-free FAs, improves post-absorptive, insulin-mediated suppression of hepatic glucose output, reduces the metabolic burden on liver and muscle, and promotes glucose utilization and insulin sensitivity [4]. Insulin resistance is often observed in nonalcoholic fatty liver disease (NAFLD) [5], which is concomitantly seen in 70\% of T2DM patients globally [6]. NAFLD is projected to become the leading cause of liver transplantation, and the risk of liver-related mortality increases exponentially with the increase in fibrosis stage [7]. Currently, no approved drug is available worldwide to treat NAFLD. However, there is ongoing clinical development on various indications of Saroglitazar like nonalcoholic steatohepatitis (NASH; NCT03863574) [8], liver transplant recipients with NAFLD (NCT03639623) [9], NAFLD women with polycystic ovary syndrome (PCOS; NCT03617263) [10], and primary biliary cholangitis (NCT03112681). These trials are in the phase II stage and, based on their outcomes, the future clinical development of Saroglitazar will be decided.

Herein, we report an interesting case of a 26-year-old male patient with diabetes whose severe hypertriglyceridemia was reduced dramatically with treatment using Saroglitazar and statin. The patient also showed a marked reduction in liver fibrosis score as measured by shear wave elastography (SWE).

\section{Case Presentation}

A 26-year-old male patient visited the outdoor clinic with his routine workplace-based check-up blood reports of sugar and lipid profiles. On examination, he did not have any signs or symptoms relating to his severely high TG or LDL-c levels. In addition, the patient did not have the financial condition to do any 


\section{Cureus}

genetic tests to exclude any familial variant or receptor-level mutations. Moreover, he did not have any significant concomitant medical history or family history.

The blood reports showed a high fasting plasma glucose and HbA1c, confirming the diagnosis of diabetes (162 mg/dl and 7.6\%, respectively). His lipid parameters were completely deranged with total cholesterol (TC), LDL, and TG being $612 \mathrm{mg} / \mathrm{dl}, 299 \mathrm{mg} / \mathrm{dl}$, and $2832 \mathrm{mg} / \mathrm{dl}$, respectively. The electrocardiograph and urine albumin-creatinine ratio were normal. By considering his severely deranged lipid profile with strikingly high LDL and TG levels, he was advised to undergo SWE (Affinity 70, Phillips N.V., Amsterdam, Netherlands) to assess the liver fat content and stiffness and obtain the liver fibrosis score. He was put on Saroglitazar $4 \mathrm{mg}$ daily along with Atorvastatin $20 \mathrm{mg}$. For his T2DM, he was advised lifestyle modifications (LSM) and was asked to re-visit the clinic after three months. However, he re-visited nearly eight months later, with new test reports, owing to job-related issues.

\section{Follow-up}

On follow-up, his blood reports showed a marked improvement in lipid parameters along with simultaneous improvements in his blood glucose profile. His fasting plasma glucose (FPG) and glycosylated hemoglobin (HbA1c) were $114 \mathrm{mg} / \mathrm{dl}$ and $6.7 \%$, respectively. The striking improvements in lipid profile were reflected by TC, LDL, and TG levels of $122 \mathrm{mg} / \mathrm{dl}, 65 \mathrm{mg} / \mathrm{dl}$, and $92 \mathrm{mg} / \mathrm{dl}$, respectively. A brief summary of the initial and follow-up data after eight months is described in Table 1.

\begin{tabular}{|c|c|c|c|c|}
\hline Laboratory Parameters & (Day 0) & $\begin{array}{l}\text { Visit } 2 \text { (After } 8 \\
\text { months) }\end{array}$ & $\begin{array}{l}\text { Absolute changes from } \\
\text { baseline }\end{array}$ & $\begin{array}{l}\% \text { change from } \\
\text { baseline }\end{array}$ \\
\hline Fasting Plasma Glucose (FPG; mg/dl) & 162 & 114 & -48 & 29.63 \\
\hline Glycosylated Hemoglobin (HbA1c; \%) & 7.6 & 6.7 & -0.9 & NA \\
\hline Total Cholesterol (TC, mg/dl) & 612 & 122 & -490 & 80.07 \\
\hline HDL Cholesterol (mg/dl) & 41 & 39 & -2 & 4.88 \\
\hline LDL Cholesterol (mg/dl) & 299 & 65 & -234 & 78.26 \\
\hline VLDL Cholesterol (mg/dl) & 272 & 18 & -254 & 93.38 \\
\hline Triglycerides (TG, mg/dl) & 2832 & 92 & $-2 / 40$ & 96.15 \\
\hline Serum ALT (U/L) & 74 & 48 & -26 & 35.14 \\
\hline $\begin{array}{l}\text { Shear Wave Elastography (SWE; mean } \\
\text { value; } \mathrm{m} / \mathrm{sec} \text { ) }\end{array}$ & 1.98 & 1.59 & -0.39 & 19.10 \\
\hline
\end{tabular}

\section{TABLE 1: Blood glucose and lipid parameters at the 1st visit and the 2nd visit after eight months}

FPG: Fasting Plasma Glucose; TC: Total Cholesterol; HDL: High-Density Lipoprotein; LDL: Low-Density Lipoprotein; VLDL: Very Low-Density Lipoprotein; TG: Triglyceride; ALT: Alanine Aminotransferase; SWE: Shear Wave Elastography

Even the liver fibrosis score came down from $1.98 \mathrm{~m} / \mathrm{sec}$ (moderate fibrosis as per the acoustic radiation force impulse (ARFI) classification) (Figure 1) to $1.59 \mathrm{~m} / \mathrm{sec}$ (mild fibrosis as per the ARFI classification) (Figure 2). 


\section{Cureus}

The Shear wave elastography value of the liver parenchyma as follows

$\begin{array}{lll}\text { Average } & : & 1.98 \mathrm{~m} / \mathrm{sec} \\ \text { Median } & : & -2.03 \mathrm{~m} / \mathrm{sec} \\ \mathrm{SD} & : & 0.25 \mathrm{~m} / \mathrm{sec}\end{array}$

IQR/ MEDIAN - 24\%.

\begin{tabular}{|l|l|}
\hline $1.00-1.5 \mathrm{~m} / \mathrm{sec}$ & Normal \\
\hline $1.5-1.75 \mathrm{~m} / \mathrm{sec}$ & Mild fibrosis \\
\hline $1.75-2.1 \mathrm{~m} / \mathrm{sec}$ & Moderate fibrosis \\
\hline $2.1 \mathrm{~m} / \mathrm{sec}$ & Severe fibrosis \\
\hline
\end{tabular}

MPRESSION : MODERATE FIBROSIS.

FIGURE 1: Baseline shearwave elastography value of the patient

\begin{tabular}{lll|}
\hline \hline $\begin{array}{l}\text { Average } \\
\text { Median }\end{array}$ & $: 1.59 \mathrm{~m} / \mathrm{sec}$ \\
SD & $: 1.54 \mathrm{~m} / \mathrm{sec}$ \\
\hline IQR $/$ MEDIAN $-21 \%$. & $0.16 \mathrm{~m} / \mathrm{sec}$ \\
\hline $1.00-1.5 \mathrm{~m} / \mathrm{sec}$ & Normal \\
\hline $1.5-1.75 \mathrm{~m} / \mathrm{sec}$ & Mild fibrosis \\
\hline $1.75-2.1 \mathrm{~m} / \mathrm{sec}$ & Moderate fibrosis \\
\hline$>2.1 \mathrm{~m} / \mathrm{sec}$ & Severe fibrosis \\
\hline
\end{tabular}

FIGURE 2: Follow-up shearwave elastography of the patient after eight months

The ARFI elastometry method noninvasively quantifies hepatic stiffness and the degree of fibrosis. For example, ARFI values of 1.5 to $1.75 \mathrm{~m} / \mathrm{s}, 1.75$ to $2.1 \mathrm{~m} / \mathrm{s}$, and $>2.1 \mathrm{~m} / \mathrm{s}$ are considered as mild, moderate, and severe liver fibrosis, respectively [11]. Other parameters that reduced from the baseline were the liver enzymes alanine aminotransferase (ALT) and aspartate aminotransferase (AST). Considering these marked reductions in fasting glucose and lipid parameters, ongoing medications were continued along with LSM.

\section{Discussion}

Insulin resistance is considered to be the core pathology for T2DM and is also associated with dyslipidemia and other metabolic complications such as NAFLD, obesity, and so on. In DD, controlling both glucose and lipid levels appears to be challenging, and a single pill addressing both the entities increases patient compliance to a huge extent. Saroglitazar is the only approved dual PPAR $a+\gamma$ agonist in India for the treatment of hypertriglyceridemia in T2DM not controlled with statin therapy. Due to its dual action on 
PPAR receptors, Saroglitazar has a reducing effect on elevated TG and a positive effect on insulin sensitivity. Randomized, controlled, phase 3 clinical trials have shown that Saroglitazar $4 \mathrm{mg}$ once daily when added to statin leads to a significant decrease in TG (-46.7\%) and non-HDL- cholesterol (HDL-C; $-32.5 \%)$ along with a significant decrease in HbA1c (-0.3\%). In addition, Saroglitazar was found to be safe and well-tolerated as well [12-13]. A previous study showed that TG was an independent marker of major adverse cardiovascular events in women as reflected by a p-value of 0.01 [14]. In recent studies, TG management has been intensified by the mortality benefits shown in the reduction of cardiovascular events with the icosapent ethyl-intervention trial (REDUCE-IT) study of NCT01492361 with the use of 4 grams per day of icosapent ethyl [15]. The ElastPQ ultrasound shear wave elastography study showed increased TG and diabetes mellitus to be independent risk factors for increased liver fibrosis as measured by SWE (p-value $<0.05$ for both) [16]. Another study also measured liver stiffness in patients having diabetes using the same SWE technique and showed that $88.88 \%$ of the study population comprising NAFLD with diabetes to be above the normal SWE value [17].

In the present case report, the absolute reductions in TC, LDL, and TG levels were $-490 \mathrm{mg} / \mathrm{dl}(80 \%$ reduction), $-234 \mathrm{mg} / \mathrm{dl}$ (78\% reduction) and $-2740 \mathrm{mg} / \mathrm{dl}$ (97\% reduction), respectively, post-treatment with atorvastatin $20 \mathrm{mg}$ and Saroglitazar $4 \mathrm{mg}$ for eight months. In addition, his blood glucose parameters were in control with an absolute reduction in FPG and HbA1c by $-48 \mathrm{mg} / \mathrm{dl}$ and $-0.9 \%$ on administering only LSMs and Saroglitazar. Being a PPAR- $\gamma$ agonist, Saroglitazar has shown improvement in insulin sensitivity in T2DM patients with hypertriglyceridemia [18]. Saroglitazar may have contributed to insulin resistance reduction by acting on PPAR- $\gamma$ receptors, resulting in improved FPG and HbA1c. In this case study, the results at the eight-month follow-up suggest that Saroglitazar improves lipid parameters as well as glycemic control. This report also highlights the significant reduction in ALT value and SWE score with this molecule, making it a promising future agent in NAFLD with DD.

\section{Conclusions}

Saroglitazar is a dual PPAR $a+\gamma$ agonist that reduces elevated TG, HbA1c, and stiffness of the liver as reflected by the reduction in the SWE score of the liver. This indicates that Saroglitazar is a dual agonist with triple benefits. Currently, Saroglitazar is under investigation for disorders related to insulin resistance.

\section{Additional Information \\ Disclosures}

Human subjects: Consent was obtained by all participants in this study. Conflicts of interest: In compliance with the ICMJE uniform disclosure form, all authors declare the following: Payment/services info: All authors have declared that no financial support was received from any organization for the submitted work. Financial relationships: All authors have declared that they have no financial relationships at present or within the previous three years with any organizations that might have an interest in the submitted work. Other relationships: All authors have declared that there are no other relationships or activities that could appear to have influenced the submitted work.

\section{References}

1. Dutta D, Ghosh S: Young-onset diabetes: an Indian perspective. Indian J Med Res. 2019, 149:441-442. 10.4103/ijmr.IJMR_1938_18

2. Mithal A, Majhi D, Shunmugavelu M, et al.: Prevalence of dyslipidemia in adult Indian diabetic patients: a cross sectional study (SOLID). Indian J Endocrinol Metab. 2014, 18:642-647.

3. Joshi SR, Anjana RM, Deepa M, et al.: Prevalence of dyslipidemia in urban and rural India: the ICMR-INDIAB study. PLoS One. 2014, 9:96808. 10.1371/journal.pone.0096808

4. Lipaglyn. Saroglitazar. Product monograph. (2019). Accessed: December 1, 2019: http://lipaglyn.com/downloads/Lipaglyn_Product_Monograph.pdf.

5. Utzschneider KM, Kahn SE: The role of insulin resistance in nonalcoholic fatty liver disease . J Clin Endocrinol Metab. 2006, 91:4753-4761. 10.1210/jc.2006-0587

6. Williams CD, Stengel J, Asike MI, et al.: Prevalence of nonalcoholic fatty liver disease and nonalcoholic steatohepatitis among a largely middle-aged population utilizing ultrasound and liver biopsy: a prospective study. Gastroenterology. 2011, 140:124-131. 10.1053/j.gastro.2010.09.038

7. Wong RJ, Aguilar M, Cheung R, et al.: Nonalcoholic steatohepatitis is the second leading etiology of liver disease among adults awaiting liver transplantation in the United States. Gastroenterology. 2015, 148:547555. 10.1053/j.gastro.2014.11.039

8. Saroglitazar magnesium in the treatment of non-alcoholic steatohepatitis . (2019). Accessed: December 1, 2019: https://clinicaltrials.gov/ct2/show/NCT03863574.

9. Safety, tolerability and efficacy of Saroglitazar Mg $4 \mathrm{mg}$ in liver transplant recipients with NAFLD . (2019). Accessed: December 1, 2019: https://clinicaltrials.gov/ct2/show/NCT03639623.

10. Saroglitazar magnesium $4 \mathrm{mg}$ in the treatment of NAFLD in women with PCOS (Evidences VII) . (2019). Accessed: December 1, 2019: https://clinicaltrials.gov/ct2/show/NCT03617263.

11. Goertz RS, Sturn J, Pfeifer L, Wildner D, Wachter DL, Neurath MF, Strobel D: ARFI cut-off values and significance of standard deviation for liver fibrosis staging in patients with chronic liver disease. Ann Hepatol. 2013, 12:935-941.

12. Pai V, Paneerselvam A, Mukhopadhyay S, et al.: Multicenter, prospective, randomized, double-blind study to evaluate the safety and efficacy of Saroglitazar 2 and $4 \mathrm{mg}$ compared to pioglitazone $45 \mathrm{mg}$ in diabetic 


\section{Cureus}

dyslipidemia (PRESSV). J Diab Sci Technol. 2014, 8:132-141. 10.1177/1932296813518680

13. Jani RH, Pai V, Jha P, Jariwala G, Mukhopadhyay S, Bhansali A, Joshi S: Multicenter, prospective, randomized, double-blind study to evaluate the safety and efficacy of Saroglitazar 2 and $4 \mathrm{mg}$ compared with placebo in type 2 diabetes mellitus patients having hypertriglyceridemia not controlled with atorvastatin therapy (Press VI). Diab Technol Ther. 2014, 16:63-71. 10.1089/dia.2013.0253

14. Prasad M, Sara JD, Widmer RJ, Lennon R, Lerman LO, Lerman A: Triglyceride and triglyceride/HDL (high density lipoprotein) ratio predict major adverse cardiovascular outcomes in women with non-obstructive coronary artery disease. J Am Heart Assoc. 2019;8, 9442:10-1161. 10.1161/JAHA.118.009442

15. Bhatt DL, Steg PG, Miller M, et al.: Cardiovascular risk reduction with icosapent ethyl for hypertriglyceridemia. N Engl J Med. 2019, 380:11-22. 10.1056/NEJMoa1812792

16. Koc AS, Sumbul HE: Prediabetes is associated with increased liver stiffness identified by noninvasive liver fibrosis assessment: ElastPQ ultrasound shear wave elastography study. Ultrasound Q. 2019, 4:330-338. 10.1097/RUQ.0000000000000419

17. Roy S, Majumder A: A retrospective study to examine the correlation of bioelectrical impedance analysis with shear-wave elastography in Indian patients with non-alcoholic fatty liver disease and diabetes on background sodium-glucose cotransporter-2 inhibitor therapy. Cureus. 2019, 11:4674. 10.7759/cureus.4674

18. Saroglitazar improves insulin sensitivity in patients of type 2 diabetes mellitus with hypertriglyceridemia- a pilot study. (2019). Accessed: December 1, 2019:

https://search.proquest.com/openview/ca2bf3c5b2f2abe88626af651fc9ee65/1?pqorigsite $=$ gscholar $\&$ cbl $=1896353$. 